\title{
Nanoeconomics of Households in Lockdown Using Agent Models during COVID-19
}

\author{
Javier Cifuentes-Faura $^{1, *(1)}$ and Renaud Di Francesco ${ }^{2}$ \\ 1 Faculty of Economics and Business, University of Murcia, 30100 Murcia, Spain \\ 2 The Institution of Engineering and Technology, London WC2E 7, UK; rdifrancesco@ymail.com \\ * Correspondence: javier.cifuentes@um.es
}

check for updates

Citation: Cifuentes-Faura, J.; Francesco, R.D. Nanoeconomics of Households in Lockdown Using Agent Models during COVID-19. Sustainability 2022, 14, 2083.

https://doi.org/10.3390/su14042083

Academic Editors: Luigi Aldieri and Sajid Anwar

Received: 9 December 2021

Accepted: 8 February 2022

Published: 11 February 2022

Publisher's Note: MDPI stays neutral with regard to jurisdictional claims in published maps and institutional affiliations.

Copyright: (C) 2022 by the authors. Licensee MDPI, Basel, Switzerland. This article is an open access article distributed under the terms and conditions of the Creative Commons Attribution (CC BY) license (https:// creativecommons.org/licenses/by/ $4.0 /)$.

\begin{abstract}
The world is experiencing a global pandemic with COVID-19, for which few measures have proven their efficiency. Prevention through lockdown belongs to the portfolio of Non-Pharmaceutical Intervention (NPI). The implementation of a lockdown comes with a potential health care benefit balanced with an economic and human cost: people are constrained to stay in their homes. Households hence have to live together in what we call "zero-space", which means within the walls of their flat or house. The loss of "space-domain" freedom, preventing them to move in "free" space is accompanied by a continued "time-domain" freedom with the possibility to allocate their time, and what they do with it, within the location they are not permitted to leave (with very defined exceptions). We study the microeconomics framework in such a setting, starting from the rules shaping such a "nano-market" with very few agents (the members of the household), and its consequence for nano-economic interaction. Since the behaviour of the agents is hyperconstrained in the space domain and relatively free in the time domain, behavioral economics is used to describe decisions made in the home, for the actions remaining possible during lockdown. A minimal set of rules is introduced and illustrated to describe efficiently the agents at play in this new and particular context, which has been replicated worldwide during the pandemic. Hypotheses for this model are presented and discussed, so as to allow future variations and adaptations for other specific cases with different options chosen. Such hypotheses concern agents, their interests, behaviours, and the equivalent of non-financial "nano-market transactions and contracts".
\end{abstract}

Keywords: COVID-19; nanoeconomics; microeconomics; behavioural economics; agent-based model

\section{Introduction}

COVID-19 was identified in Wuhan in December 2019 and spread rapidly worldwide, causing billions of infections and deaths, affecting every country [1-3]. This is an unprecedented health, social and economic crisis $[4,5]$. To curb the spread of this pandemic, many governments have imposed, at different phases of the propagation of the virus, restrictive measures called Non-Pharmaceutical Interventions (NPI), which were the only ones available [6] prior to the development and availability of vaccines against the virus, and more recently of treatments for patients infected by the virus. Among those measures, which include reinforced hygiene and distance-keeping between humans, a last resort government intervention is home confinement of everyone, with exceptions such as health care or food sector workers. Such measure now commonly known as "lock-down", forces everyone to stay at home with only a few essential reasons acceptable for leaving home a short time per day. Whenever possible, working online from home allowed some continuity of operations in the economy [7-9] beyond essential domains such as health care and food.

The COVID-19 pandemic has also generated changes in attitude for part of the population. Human beings were again observed to live in an environment in which there is asymmetric information, and in which the optimization of self-interest by agents is not the only motivation and preference [10]. 
Behavioral Economics methods have come to the forefront [11] during the pandemic, as public decision-makers had to implement Non-Pharmaceutical Interventions [6] in the absence of any other protection means. A pre-requisite for the success of NPI implementation was for the citizens to agree with the goal set, and follow the measures decided by the government. NPIs formalized in law would not only rely on police enforcement, but on encouraging target behaviours in citizens. Therefore, behaviours were nudged [12] towards health preserving attitudes, through communication campaigns of government and advising scientific bodies.

The human mind has restrictions in processing information and analyzing it [13] and, on many occasions, biased decisions are triggered by immediate impressions not being followed by a reflection time, while other biased mechanisms of decisions are already present due to unchallenged past biases which have become habits in our behavioural decision process [14]. The behavioural biases that people may have during this coronavirus crisis can influence their reluctance towards government responses and impede reaching a goal deemed beneficial for society. Therefore, a better understanding of the meaning of how "zero-space" constraints impact all household members, as agents of a "nano-market" on which tasks and roles are subject of interaction and transaction. Conversely, the light cast on this specific case is expected to provide an illustration of principles of behavioural economics, giving a sound starting base for nudging towards desired behaviours, which society needs during this pandemic.

\section{Behavioral Economics and Biases during COVID-19}

The role of the individual's behavior in his economic behavior as an agent is not a new topic; its origin can be found in the economic framework described by Adam Smith. However, the starting economic model of self-interest optimization by agents has been enriched and modified since, with more thorough considerations at the crossroads of collective versus individual optimization mechanisms, including altruistic behaviours, and other psychologically identified human behaviors. The fundamental disciplines underpinning behavioral economics are drawn from economics and psychology, but have also diversified and incorporated ideas from sociology, anthropology, and neuroscience $[15,16]$.

Behavioral economics has been applied efficiently in the field of health with the purpose to improve people's habits for their own benefit $[17,18]$. Hence, leveraging behavioural economics to address societal issues arising in COVID-19 seemed natural. Through small nudges, or the so-called "Nudge" [12], individuals are guided towards a choice, by casting light on benefits, however without restricting or limiting the options available. Citizens should have the ability to decide on what suits their lives rationally. Thaler and Sustein [12] define nudge as "Any aspect of the choice architecture that alters people's behavior in a predictable way without prohibiting any choice or significantly changing their economic incentives".

Ashraf et al. [19] argue that Adam Smith, who is often considered the founder of economics, was a behavioral economist. There are three important concepts of behavioral economics: loss aversion, overconfidence, and self-control [20]. Regarding loss aversion, Smith [21] noted that "pain is, in most cases, a more pungent sensation than the opposite and corresponding pleasure." As for overconfidence, Smith [22] alluded to "the smug conceit which most men have of their own abilities," which leads them to overestimate their chances of success. Finally, regarding self-control, now called "present bias", Smith [21] stated: "The pleasure we shall enjoy ten years hence is of very little interest to us in comparison with that which we can enjoy today".

In Keynes' General Theory, Keynes anticipated what is now known as behavioral finance. He observed that "the daily fluctuations of the returns on existing investments, which are obviously of an ephemeral and insignificant character, tend to exert an excessive and even absurd influence on the market" [23]. Several other economists also thought that psychology should play an important role in economics. For instance, Pareto [24] noted that "The foundation of political economy and, in general, of all social science is evidently 
psychology. Perhaps the day will come when we will be able to decide the laws of social science from the principles of psychology".

The crisis caused by the coronavirus has led Behavioral Economics to acquire a relevant role in curbing the pandemic and making decisions $[25,26]$. The pandemic has also led to the emergence of biases related to human behavior, which have been aggravated by the existing misinformation [27-29].

Cognitive biases describe disturbances in the human mind that are difficult to eliminate and lead to distortion of perception, inaccurate judgment, or illogical interpretation [30-32]. We can fundamentally distinguish the following biases, during the COVID-19 pandemic.

- Hindsight bias. Once people know that an event has occurred, they delude themselves into thinking that they knew that event would occur $[33,34]$. This bias causes people to perceive any new information about the fight against COVID-19 as inevitable, and leads them to believe that policy makers should have known the direction of the COVID-19 pandemic, causing them to question the credibility of the government.

- Confirmation bias. Human beings take the information which supports their predefined view and ignore what would contradict it $[35,36]$. This bias has played a role in observed deviations in individual behaviors, from the common societal goals generally agreed in the coronavirus pandemic.

- Optimism bias. Human beings are convinced that they will be luckier than others, and that negative situations do not affect them [37,38]. Part of the population thinks that COVID-19 will not affect them, because of their age group or other categories they belong to, and they skip restrictions, putting vulnerable people, such as the elderly at risk.

- Present bias. The brain tends to think and act instantaneously, prefering immediate reward versus future gratification [39]. Therefore, during COVID-19, some people may have tried to seek the maximum current benefit, as enjoying participation at a large event (such as a football game), at the risk of contributing to super-spreading the virus, as opposed to waiting for the pandemic status to allow for it safely again.

- Loss aversion bias: human beings do not invest simply because of the possibility of losing [40], since individuals suffer more when they lose than when they win [41]. Observed reluctance of some towards the vaccine, in its early stage of availability, might be attributed partly to this bias: the gain of protection for say 6 months given by a vaccine, versus a potential unknown risk in the very long term. In this case, the long term individual loss aversion comes in the way of immediate benefit for all.

- The bandwagon effect. Individuals do something only because the people around them do it $[42,43]$. This can lead to the human being tending to perform a certain action in the pandemic only because other people of the same status are doing them, even if they are not correct. An illustration has been observed in groups of opponents to vaccination, reinforcing each other's behaviours with social networks and direct discussion and circulation of conspiracy theories and fake news.

- The illusion of control bias. Humans like to think that they have some control over their environment $[44,45]$. The control illusion bias causes you to believe that you can influence random phenomena or phenomena that are totally beyond your influence, such as COVID-19. Individuals believe that performing specific actions, such as compulsive shopping at the supermarket, can allow them to control the situation. Stockpiling actions have been observed in the early phase of the pandemic, leading to shortages in toilet paper.

- The recent experience bias. The brain places more importance on the latest data or the most recent experience [46]. This bias causes us to look only at the latest most recent events to make decisions, so COVID-19-derived events have a strong influence on our day-to-day decisions. Whenever daily death statistics improve, a trend for behaviours to deviate from strict distancing, hygiene and wearing face masks can be observed, as if the pandemic was over, and the mid to long term memory of contagion waves and peaks seems to get lost. 
- Conservation bias. This is the tendency to give more importance to the first analysis and disregard the new information you receive $[47,48]$. Once we have analyzed a COVID-19 relevant information, many citizens may have to dismiss new ideas.

These biases can influence human behavior during the pandemic [49], the individual's purchasing process or household savings decisions and the day-to-day life of the individual. In order to perform certain behaviors or actions, agents need some stimulus or motivations [50]. In the case of the pandemic, behaviours would need adaptations to accommodate for new conditions on public transport and in shops (mask requirement) and postponing events, reducing close social contacts, but habits are kept such as company or organization Christmas parties (Ex of UK government staff disrespecting their own rules because parties were felt necessary, and the need to change not seen).

\section{Zero-Space during Lock-Down Phase in the Pandemic}

In this section, we describe a realistic model of a household under lock-down and analyze how optimization and trade-offs might be necessary for the satisfaction of individual household members and their economic well-being.

Household Members

Household members can be categorized by age, as a child, teenager, adult, or elderly person.

In the first scenario, below, we will restrict ourselves to the case of children and adults who either work from home or do not work during the lockdown, to be revisited later, but not in the present article, to include the case of essential workers. A teenager may be asked to sometimes supervise a child, but he/she may also have to attend own Education sessions and perform associated tasks.

Activities of household members

We will consider a subset of all real activities expected to happen in a household, for the sake of microeconomic/nano-economic modelling:

- Work, for an adult, coined as "Work from Home" (WFH abbreviated into W here);

- Children play supervision by an adult (CSA, abbreviated into C);

- $\quad$ Education for a child, by an adult as a local tutor, Education in Home (EIH);

- Education, for a child, attending remote sessions in Education from home (EFH);

- Home, for adults: preparing meals, keeping the house tidy;

- $\quad$ Leisure, for a child, or for an adult, as zero-space leisure (ZSL).

Time: horizon and schedule

We consider a work week of 5 days Monday to Friday, followed by 2 days of weekend. In the first scenario where work considered is work from home exclusively (WFH), $\mathrm{W}$ is done from Monday to Friday, with work hours added up every day, and expected to equal the daily total of the contract.

We consider two meal schedules, around the perceived needs of the children of the household: the weekday meal schedule, and the weekend day meal schedule.

The time horizon of the day is from 00:00 to 24:00, and it is denoted by T.

The meals are breakfast, lunch, tea and dinner. The $k t h$ meal of the day must be ready at time $t_{k}$ and it requires $d_{k}$ preparation time by an adult. More precisely, the amount of adult preparation time totals $d_{k}$, and the preparation task can be split across several adults.

Children have a fixed Education from Home (EFH) schedule, and a flexible Education in the Home schedule.

\section{Agents and Beneficiaries}

We consider two types of agents in the first scenario: adults and school-age children. The set of adults in the household is $\mathrm{A}^{\prime}$, the set of children in the household is $\mathrm{C}^{\prime}$. We also define beneficiaries as symbolic entities: "work" denoted W, "children" denoted C, "education" denoted E, "home" denoted $\mathrm{H}$, and "leisure" denoted $\mathrm{L}$

The set $\mathrm{B}$ of beneficiaries in the present scenario is

$B=\{W, C, E, H, L\}$ 


\section{Rules}

Daily operations constraints on Week-days

At any given time, $t$, an adult $a$ is assumed to dedicate their time to a single beneficiary. The single beneficiary of the activity of adult $a$ at time $t$ is denoted by $\mathrm{b}(a, \mathrm{t}) \in \mathrm{B}$

$$
\begin{aligned}
& \mathrm{b}: \mathrm{A}^{\prime} \mathrm{xT} \rightarrow \mathrm{B} \\
& (a, t) \rightarrow \mathrm{b}(a, t)
\end{aligned}
$$

An agent can perform multitasking. Let us express the rules concerning each beneficiary of tasks performed by adults in households, by stating first their text description, then their mathematical expression

\section{Children supervision rule}

$\mathrm{R}(\mathrm{C})$ : At any time $t$, one of the adults is tasked with the supervision of the children (freeing the other adults for other tasks)

$\mathrm{R}(\mathrm{C}): \forall t \in \mathrm{T}, \exists a \in \mathbf{A}^{\prime}, \mathrm{b}(a, t)=\mathrm{C}$

Meal (House) rule

$\mathrm{R}(\mathrm{H})$ : Each of the $\mathrm{k}$ meals of the day has a schedule: it must be ready at $t_{k}$ and needs a total preparation time by adults of $d_{k}$

$\mathbf{R}(\mathrm{H}):$ Card $\left\{t<t_{k} / \exists a \in \mathrm{A}^{\prime}, \mathrm{b}(a, t)=\mathrm{H}\right\} \geq d_{k}$

Working from Home contractual hours rule

$\mathrm{R}(\mathrm{W})$ : Every adult working from home respects the contractual working hours per day, w(a)

$\mathrm{R}(\mathrm{H}):$ Card $\left\{t<t_{k} / \exists a \in \mathrm{A}^{\prime}, \mathrm{b}(a, t)=\mathrm{H}\right\} \geq d_{k}$

\section{Education rules}

Let us now consider the commitments expected from the school-age children, regarding education, as EFH, and EIH.

$\mathrm{R}(\mathrm{E})$ : Child $c$ attends their EFH sessions according to schedule of remote school sessions e(c)

$\mathbf{R}(\mathrm{E}): \forall c \in \mathbf{C}^{\prime}, \forall t \in \mathbf{e}(c), \mathbf{b}(c, t)=\mathbf{E}$

Note that during such a session, the child is assumed to be supervised by the remote tutor giving the lesson. If all children in the household have time overlaps in EFH, during such time every adult of the household is freed from supervising the children.

This property has been sought after by parents in lockdown. The education rule above is replicated for non-curricular activities such as music, arts, or remote tuitions or activities supervised by a remote tutor, call it $\mathrm{E}^{\prime}$ to distinguish it from curricular education activities E.

$\mathbf{R}\left(\mathrm{E}^{\prime}\right): \forall c \in \mathbf{C}^{\prime}, \forall t \in \mathbf{e}^{\prime}(c), \mathbf{b}(c, t)=\mathrm{E}^{\prime}$

which translates into an embedded remote "baby-sitting" effect if extra-curricular activities are scheduled identically for all children in household:

$\forall c^{\prime} \in \mathbf{C}^{\prime}, \forall c^{\prime \prime} \in \mathbf{C}^{\prime}, \mathbf{e}^{\prime}\left(c^{\prime}\right)=\mathbf{e}^{\prime}\left(c^{\prime \prime}\right)$

Furthermore, even if the schedules of each child varies slightly, there is an interest to increase the intersection of those schedules:

- Define:

$\mathrm{e}^{\prime \prime}(c)=\mathrm{e}(c) \cup \mathrm{e}^{\prime}(c)$

$\mathrm{e}^{\prime \prime}\left(\mathrm{C}^{\prime}\right)=\cap_{c \in C^{\prime}} e^{\prime \prime}(c)$

This allows us to rewrite a less restrictive children supervision rule

Children supervision rule with remote education (curricular and extra-curricular)

$\mathrm{R}\left(\mathrm{C} \cap \mathrm{E}^{\prime \prime}\right): \forall t \in \mathrm{T}-\mathrm{e}^{\prime \prime}\left(\mathrm{C}^{\prime}\right), \exists a \in \mathrm{A}^{\prime}, \mathrm{b}(a, t)=\mathrm{C}$

This means that all adults are freed during the common children schedule $\mathrm{e}^{\prime \prime}\left(\mathrm{C}^{\prime}\right)$. They can either work or have a leisure break.

We can introduce economic reasoning at this point: how is the increase of $\mathrm{e}^{\prime \prime}\left(\mathrm{C}^{\prime}\right)$ valued by adults in the household? This will determine partly their readiness to pay for the extra-curricular remote tutors delivering schedule $\cup_{c \in C^{\prime}} e^{\prime}(c)$. 
Naturally, the overall marginal value of such remote extra-curricular tutoring sessions should take account of keeping the children entertained, happy, interested, stimulated to learn or practice a skill or interest.

\section{Curricular education in question during lockdown}

The experience of Education from home (EFH) where teachers who normally teach their class at school, as EOH Education out of home, moved online to teach and tutor their students within the school curriculum has been extremely varied across countries [51-53] and across schools, even depending on teachers.

Some were in the mindset of WFH and teaching remotely, and others rather not, with added constraints likely in their own households.

\section{Different Activities of the Members of the Household and Agent-Based Model Theory}

Agents can be considered as resources, and activities as requesters. We exemplify how a day plays out in what we call "zero space", during lock-down. An example of schedule for a household comprising two parents, agents $a^{\prime}$ and $a^{\prime \prime}$, and two children $c^{\prime}$ and $c^{\prime \prime}$, with the two parents working from home (WFH) abbreviated here as $\mathrm{W}$, and the two children engaged in Education from Home (EFH) abbreviated as E, with extracurricular activities for children being denoted $\mathrm{E}^{\prime}$ as above. Activity relative to the House is denoted by $\mathrm{H}$, and children play or leisure as well as leisure for adults being denoted by L. Let us recall that $C$ denotes children supervision by an adult. The symbol "_" stands for sleeping in bed.

For a daily schedule of $11 \mathrm{~h}$, going from 1st to 11th, we can put together this example of a schedule (Table 1).

Table 1. Day schedule of $11 \mathrm{~h}$.

\begin{tabular}{ccccc}
\hline Hour & $\mathbf{a}^{\prime}$ & $\mathbf{a}^{\prime \prime}$ & $\mathbf{c}^{\prime}$ & $\mathbf{c}^{\prime \prime}$ \\
\hline 1 & $\mathrm{C}$ & $\mathrm{W}$ & $\mathrm{L}$ & $\mathrm{L}$ \\
\hline 2 & $\mathrm{~W}$ & $\mathrm{C}$ & $\mathrm{L}$ & $\mathrm{E}$ \\
\hline 3 & $\mathrm{C}$ & $\mathrm{W}$ & $\mathrm{L}$ & $\mathrm{L}$ \\
\hline 4 & $\mathrm{C}$ & $\mathrm{W}$ & $\mathrm{E}$ & $\mathrm{L}$ \\
\hline 5 & $\mathrm{~L}$ & $\mathrm{H}$ & $\mathrm{E}$ & $\mathrm{E}$ \\
\hline 6 & $\mathrm{~W}$ & $\mathrm{C}$ & $\mathrm{L}$ & $\mathrm{L}$ \\
\hline 7 & $\mathrm{C}$ & $\mathrm{W}$ & $\mathrm{L}$ & $\mathrm{L}$ \\
\hline 8 & W & $\mathrm{L}$ & $\mathrm{L}$ & $\mathrm{L}$ \\
\hline 9 & $\mathrm{H}$ & $\mathrm{C}$ & $\mathrm{L}$ & $\mathrm{L}$ \\
\hline 10 & $\mathrm{C}$ & $\mathrm{L}$ & $\mathrm{L}$ & $\mathrm{L}$ \\
\hline 11 & $\mathrm{~L}$ & $\mathrm{~L}$ & - & - \\
\hline
\end{tabular}

How do we observe activities competing for the attention of an agent?

Work (W) needs tasks from $a^{\prime}$, so does the House (meals preparation, etc.), and the children who need supervision, some leisure for pleasure and individual balance of agent $a^{\prime}$, who nobodies want to get depressed in the lockdown phase.

W gets served by $a^{\prime}$ at time slot 2, 6, and 8 . H gets served by $a^{\prime}$ at timeslot 9 .

This task allocation represented by a schedule is similar to a client-server model in computer science: activities are beneficiaries, and agents are resources.

The allocation of time and resources in the "zero space" (lockdown) during the pandemic can be compared to a model of monastic life such as that of the Abbaye of Solesmes in France (Table 2) (for more information: Abbaye Saint Pierre, Solesmes "A Day in the Life of a Monk" https: / / www.solesmes.com/day-life-monk (accessed on 10 October 2021)), where most of the activities have a religious character, denoted by " $R$ ". The other activities include work (in our notation "W") and meals: 
Table 2. Weekdays schedule of a monk.

\begin{tabular}{|c|c|}
\hline Time & Task \\
\hline 5:00 & Rise \\
\hline $5: 30$ & Office of Vigils \\
\hline $6: 45$ & Breakfast \\
\hline 7:00 & Personal Prayer or Reading \\
\hline $7: 30$ & Office of Lauds \\
\hline $8: 10$ & Lectio divina \\
\hline 10:00 & Mass \\
\hline 11:15 & Work \\
\hline 13:00 & Office of Sext \\
\hline $13: 15$ & Lunch \\
\hline $13: 50$ & Office of None \\
\hline $14: 00$ & Recreation \\
\hline $14: 50$ & Work \\
\hline 17:00 & Office of Vespers \\
\hline $17: 30$ & Personal Prayer or Reading \\
\hline 19:30 & Supper \\
\hline 20:00 & Personal Prayer \\
\hline $20: 30$ & $\begin{array}{l}\text { Community meeting in the chapter house, during which the Abbot } \\
\text { provides teaching, followed by Compline }\end{array}$ \\
\hline 21:00 & Night Silence \\
\hline
\end{tabular}

Let us now go back to the households under study, in the scenario of WFH and EFH complemented by E'FH.

A model more detailed than the above might describe the "quality time" from a W perspective: uninterrupted work, versus interruptions in work (dog barking in zoom conference calls, etc.).

A more structural question for the $\mathrm{W}$ category is if such work has to happen at a defined time, because it is a real-time conferencing session with multiple participants, or if it can be agreed on the fly by two parties as on an old-fashioned phone call where a caller tries to reach someone and may or may not succeed, possibly leaving a message asking to be called back if unsuccessful, or as a one to one online chat session. Alternatively, can the task within work be performed "offline", i.e., with a deadline to complete but no fixed time to execute, as reading and writing an e-mail, preparing a document, remotely configuring a system?

In short Work W has sub-categories:

- $\quad$ Scheduled real time work task (Ex: video conferencing with multiple participants);

- Tentatively synchronous work, with best effort assumed and no guarantee of success

(Ex two party phone call, or online chat session);

- Offline task (Ex: e-mail, document).

Employers are aware of the households' constraints and the scheduling of real time tasks will be done in a flexible way, with long advanced notice.

One could note that Employer support for reducing the $\mathrm{C}$ or $\mathrm{H}$ commitment from their workers, through mutually agreeable $\mathrm{E}^{\prime}$ services or $\mathrm{H}^{\prime}$ (introducing here meal deliveries, commercially available in many locations) from third parties facilitated by the Employer might prove quite beneficial to the productivity of the employee operating under $\mathrm{WFH}$, with reduced constraints. 


\section{Inter-temporal choice and activity substitutions}

The example of schedule given above for the sake of illustration leads to ask the question of satisfaction of the stakeholders:

- $\quad$ Agents: members of the household;

- Beneficiaries: as W for Work (employers), as E for Education (schools and training institutions), E' for suppliers of extra-curricular remote activities, L for suppliers in the area of leisure consumptions (movies, music, games, physical fitness, etc.), $\mathrm{H}$ for home/house using consumable supplies (food, hygiene and cleaning products, etc.), and $\mathrm{H}^{\prime}$ for the meal deliveries for instance.

All the stakeholders mentioned are taking part in an active economic game, referring in this instance to game theory; however, with added insight from behavioural economics described above, this nano-economic game amounts to an iterative cooperative search for improvements, if not optimal solutions agreeable and beneficial to all.

A rank 1 activity modification of a given schedule would be a substitution of an activity $b^{\prime}$ allocated to an agent $a$ at a time slot $t$ by another activity $b^{\prime \prime}$.

There may be a timed activity preference of $\left(a, t, b^{\prime \prime}\right)$ by agent $a$ at time $t$, over $\left(a, t, b^{\prime}\right)$.

A rank 1, time modification (commonly called time shift) would be a time substitution, replacing $t$ by $t^{\prime}$ and the execution of $(a, t, b)$ by $\left(a, t^{\prime}, b\right)$.

An activity switch may happen between $a^{\prime}$ and $a^{\prime \prime}$; for instance, assume $\left(a^{\prime}, t, \mathrm{C}\right)$ and $\left(a^{\prime \prime}, t, \mathrm{H}\right)$ in the initial schedule, then in a transformed schedule, one could have $\left(a^{\prime}, t, \mathrm{H}\right)$ and $\left(a^{\prime \prime}, t, \mathrm{C}\right)$, as a switch of $(\mathrm{C}, \mathrm{H})$ to $(\mathrm{H}, \mathrm{C})$ between $a^{\prime}$ and $a^{\prime \prime}$.

Assume that $a^{\prime}$ likes H more than C (cooking over child supervision) and that $a^{\prime \prime}$ likes $\mathrm{C}$ more than $\mathrm{H}$ (child supervision over cooking), then a switch giving $\mathrm{H}$ to $a^{\prime}$ and $\mathrm{C}$ to $a^{\prime \prime}$ instead of $\mathrm{C}$ to $a^{\prime}$ and $\mathrm{H}$ to $a^{\prime \prime}$ is of mutual interest, and maybe of interest to $\mathrm{C}$ (the children: they get a friendlier supervision and a better meal).

Some organisations are subjects of jokes on misallocations of activities. In the conscription armies, trained hairdressers would be cooks and trained cooks would be hairdressers.

In the households considered, optimum scheduling could be a general aim. Fair scheduling should also be a criterion in this optimization, to correct as much as possible unfairness observed in the IFS study referred above. Time is the main resource, for and from every agent in the particular context of "zero-space" lockdown.

Whereas in economic science it has been customary to formulate choice and preference with utility, a measure of the interest from an agent a for a good, and to look at rigidly modeling the utility perceived at time $t$ on a future time horizon beyond $t$, by weighting future utilities at times above $t$ by a weighting factor $\mathrm{g}(t)$ (called a discount factor), we do not see the point of any such model in the case studied here.

Furthermore, there are many examples where the discounted utility model is meaningless: for instance, many people value special anniversaries, birthdays, religious or civil society celebrations (Christmas, Easter, Labour Day, Mother's Day), giving as many counterexamples over discounted utility models when it comes to inter-temporal preference. In a strictly discounted utility model, you should want to celebrate your birthday now, not on your birth's day.

Many of us have personal experience of people's very strong preference for marked calendar day visits (Ashes, Christmas Day, Easter, Mother's Day) over any other day sooner at the time of proposal. This amounts to a Dirac comb time preference for visits which allocates an infinite score to marked calendar days, and zero score to the other candidate days.

However, economic science has not been able to discard or discount the discounted utility model as their systematically preferred approach to inter-temporal choice in the last 100 years, and it has failed to consider any of the obvious counterexamples above, which are known to all of us.

The description of deadlocked households would encourage the use of game-theoretic models, in which agents and beneficiaries (stakeholders) play cooperatively for mutual benefit, and business activities are allocated for the gradual improvement of their satisfaction. 
The satisfaction of the individual members of these households and their economic welfare are influenced by behavioral biases. Thus, for example, there will be household members who will be affected by the present bias during COVID-19 and will seek the maximum current benefit, others will be affected by the bandwagon effect and will act in a certain way only because the people around them do so, and others will be aware of the recent experience bias, so they will make their decisions based on the latest recent events derived from COVID-19.

\section{Household with no children in the house}

This may describe many, for instance, those with grown-up children, those with no children yet, and those without children for any reason. In this case, we assume only adults in working from home positions, and leave for later students, those who cannot work from home in their roles, and those who are essential workers and work anyway during lockdown.

Then, the set of beneficiaries reduces:

B $=\{\mathbf{W}, \mathbf{H}, \mathbf{L}\}$

Life can be enjoyed, without the light of younger people requiring attention.

This may be of interest to the aggregated beneficiaries of:

- W:

Work, employers of the adults in the household can freely schedule meetings. In practice many have worked more in lockdown than in previous pre-pandemic normal conditions. Business travel is suppressed, more time is available, even across time-zones for anyone with an international role.

- $\mathrm{H}$ :

A re-purposing of restaurants and restaurant supplies can happen, with home delivery on a consumer market of goods previously supplied in business to business on a professional market (restaurants, bars, hotels, event and organisation catering)

This alleviate the time burden of $\mathrm{H}$ for household members, and it shifts their meal preparation partly to the $\mathrm{H}^{\prime}$ option described previously, as the delivery of meal as a service, to your door.

- L:

leading market opportunities include: online leisure, encompassing content, experience; physical training to stay fit, and any other activity, encompassing as a special case the branch E' of extra-curricular activities described earlier for children, but which also exist for adults. In short the opportunities spread widely across Training, Learning, Doing, Moving ... within "zero-space".

Time is freed from business trips and city or country leisure, and it is given back to indoor consumption (here " $\mathrm{L}$ " as a beneficiary of this time allocation). Online consumption with home delivery is part of this $\mathrm{L}$.

There is no structural need for a detailed coordination of schedules between adults in WFH roles in the household.

Network and digital systems as a lifeline

The common thread allowing the three beneficiaries to stay active in a sustainable way during lockdown is the digital infrastructure of the house, connected to the outside by networks (broadband or mobile).

The available capacity and the stability of communication protocols at a given time may be a bottleneck, since everyone is online all the time during a lockdown.

Companies and organisations had to work with urgency on the upgrade of the number of concurrent remote access supported by their servers and their digital infrastructure (VPN for instance).

However, network operators have not experienced dramatic blackouts one could have feared might happen. Neither was there any notable electrical blackout. This may be easier to explain, since professional demand for electricity usually is higher than residential 
demand, therefore the shift to almost-all demand becoming residential may have been easier to absorb.

\section{Household with no Working from Home}

Let us now come to the frequent case where it has not been possible for the adults of the household in employment to continue their work during the lockdown.

This work may not have been possible to do in the form of working from home, or they may have been prevented by their employer to perform any possible work task, because a government support scheme such as a furlough scheme, did not allow for it.

We therefore assume that beneficiary $\mathrm{W}$ is not present, but we can re-generate all others, and the set of beneficiaries $B$ can be taken as

\section{$B=\{C, E, H, L\}$}

Hence, the household can be assumed to have children and their education as a first requirement, house operation (meals), and anything else is leisure.

In this case, even more than in the preceding one, $\mathrm{L}$ is the king of markets, for young and old.

The challenge for adults used to work every day is to keep a positive mindset, and stay healthy at a time they cannot move, nor work, and social interaction with the outside missed in this way needs to be compensated in other ways. Hence, a likely reinforced use of social networks, virtual shared drinks and meals, "online get together".

These models theoretically demonstrate the behaviors of individuals during COVID19 according to their preferences and biases. Depending on the type of household and the type of individuals, different decisions will be made.

\section{Discussion and Conclusions}

Non-Pharmaceutical Interventions called for by the pandemic progress and its impact or expected impact can lead to mental and physical discomfort in individuals, and in general disturb the economy further. Governments have in their mission to ensure that the goals of NPI are understood, and that the NPIs are supported positively by the citizens. Keeping a positive mindset is helped by communication which is aware of the behavioural biases described above.

Uninterrupted cohabitation among household members can be demanding and weigh heavy on people, unless good practice and fair sharing of tasks is promoted as nanoaccompanying measures to NPI, recommending and nudging for an adequate and collectively agreed plan for the use of space and time of household members in what is their local "nano-economic market" for the duration of the lockdown.

During confinement, some people experience anxiety or boredom when they eat or drink excessively to alleviate these feelings. Therefore, they should be offered a plan of action that provides healthier choices.

The experience of Working from Home before COVID-19 had not been widely shared. Most people having to work remotely for the first time had to learn how to combine work, family and leisure responsibilities. There is also a huge gap between the functioning of a family that lives in a large house, where everyone has their own room and appropriate equipment for remote work and learning, and a family without such conditions. A work schedule became more necessary than ever, next to a calendar of activities in the family. Work and leisure spaces had to be defined anew within the homes, wherever possible, with the known issue of less affluent families not being able to accommodate sufficient education/learning space and infrastructure for homeschooling.

Students were used to having a teacher guiding them throughout the learning process. They experienced less control and guidance from a teacher, and they had to find their way into more autonomous learning. Children also need to play, so time should be planned for this. This playtime should be shared with a household member or online events should be organised to keep the connection between children and friends or classmates.

The additional interventions or nudges proposed above, scientifically rooted in behavioural economics, aim to modify behaviours without restricting people's ability to choose. 
This paper has reviewed the nano-economics of households under lockdown, modelled using agent models and behavioural economics and the nudging of health-protecting behaviours in the population by policy makers, using behavioural economics methods in their implementation of NPI measures. It has been shown theoretically through modeling and agent-based model theory, different activities that families can perform during COVID-19.

This work has various limitations. The lack of availability of much data concerning family households during confinement makes it necessary to present a theoretical model to show economic modeling and household behavior. It has left questions of interest unanswered, and open for further theoretical research, including households with essential workers, teachers and their class during lockdown, household income and effect on comparative well-being during lockdown and desirable policies addressing issues observed during lockdown.

Furthermore, possible paths and trends could be further investigated in the future such as a societal mindset evolution, geared towards more sharing and cooperation, a stronger market competition, which uses to its advantage leverages such as the digital economy, working from home, home delivery, food take-out, a potential labour force recognition to the benefit of workers in sectors called essential during the pandemic: health, care, logistics, food and catering and restarting economic activities paralysed by the pandemic, in domains such as the restaurant, hospitality, entertainment, travel and tourism business.

Author Contributions: Conceptualization, J.C.-F.; methodology, J.C.-F. and R.D.F.; validation, R.D.F.; formal analysis, R.D.F.; investigation, J.C.-F. and R.D.F.; writing-original draft preparation, J.C.-F. and R.D.F.; writing-review and editing, J.C.-F.; supervision, J.C.-F. All authors have read and agreed to the published version of the manuscript.

Funding: This research received no external funding.

Institutional Review Board Statement: Not applicable.

Informed Consent Statement: Not applicable.

Data Availability Statement: Not applicable.

Conflicts of Interest: The authors declare no conflict of interest.

\section{References}

1. Velavan, T.P.; Meyer, C.G. The COVID-19 epidemic. Trop. Med. Int. Health 2020, 25, 278. [CrossRef] [PubMed]

2. Cruz, M.P.; Santos, E.; Cervantes, M.V.; Juárez, M.L. COVID-19, a worldwide public health emergency. Rev. Clín. Esp. 2021, 221, 55-61. [CrossRef]

3. Adams, J.G.; Walls, R.M. Supporting the Health Care Workforce During the COVID-19 Global Epidemic. JAMA 2020, $323,1439$. [CrossRef] [PubMed]

4. Nicola, M.; Alsafi, Z.; Sohrabi, C.; Kerwan, A.; Al-Jabir, A.; Iosifidis, C.; Agha, M.; Agha, R. The socio-economic implications of the coronavirus pandemic (COVID-19): A review. Int. J. Surg. 2020, 78, 185-193. [CrossRef]

5. Cifuentes-Faura, J. Crisis del coronavirus: Impacto y medidas económicas en Europa y en el mundo. Espaço Econ. Rev. Bras. Geogr. Econ. 2020, 18. [CrossRef]

6. Morse, S. Pandemic Lessons. Disaster Med. Public Health Prep. 2020, 14, 427-428. [CrossRef]

7. Ammar, A.; Chtourou, H.; Boukhris, O.; Trabelsi, K.; Masmoudi, L.; Brach, M.; Bouaziz, B.; Bentlage, E.; How, D.; Ahmed, M.; et al COVID-19 Home Confinement Negatively Impacts Social Participation and Life Satisfaction: A Worldwide Multicenter Study. Int. J. Environ. Res. Public Health 2020, 17, 6237. [CrossRef]

8. Van Lancker, W.; Parolin, Z. COVID-19, school closures, and child poverty: A social crisis in the making. Lancet Public Health 2020, 5, e243-e244. [CrossRef]

9. Cifuentes-Faura, J. Analysis of containment measures and economic policies arising from COVID-19 in the European Union. Int. Rev. Appl. Econ. 2021, 35, 242-255. [CrossRef]

10. Cifuentes-Faura, J.; Di Francesco, R. Microeconomics of intertemporal choice in zero-space during COVID-19: A behavioral economics perspective. Eur. J. Health Econ. 2021, 1-5. [CrossRef]

11. Soofi, M.; Najafi, F.; Karami-Matin, B. Using Insights from Behavioral Economics to Mitigate the Spread of COVID-19. Appl. Health Econ. Health Policy 2020, 18, 345-350. [CrossRef]

12. Thaler, R.H.; Sunstein, C.R. Nudge: Improving Decisions about Health, Wealth, and Happiness; Yale University Press: New Haven, CT, USA, 2008 . 
13. Kahneman, D.; Tversky, A. Choices, Values, and Frames. In Handbook of the Fundamentals of Financial Decision Making: Part I; 2013; pp. 269-278. Available online: https:/ / econpapers.repec.org/bookchap/wsiwschap/9789814417358_5f0016.htm (accessed on 8 October 2021).

14. Duhigg, C. How Companies Learn Your Secrets. New York Times, 2013. Available online: http://www.nytimes.com/2012/02/19 /magazine/shopping-habits.html (accessed on 10 June 2021).

15. Camerer, F.C.; Lowenstein, G. Behavioral Economics: Past, Present, Future. In Advances in Behavioral Economics; Princeton University Press: New York, NY, USA, 2004; pp. 1-51.

16. Bruni, L.; Sudgen, R. The road not taken: How psychology was removed from economics, and how it might be brought back. Econ. J. 2007, 117, 146-173. [CrossRef]

17. Roberto, C.A.; Kawachi, I. (Eds.) An Introduction to Behavioral Economics and Public Health; Oxford University Press: New York, NY, USA, 2015.

18. Samson, A. The Behavioral Economics Guide 2017 (with an Introduction by Cass Sunstein). Behavioral Economic Group, 2017. Available online: https:/ / www.behavioraleconomics.com/be-guide/the-behavioral-economics-guide-2017/ (accessed on 15 June 2021).

19. Ashraf, N.; Camerer, C.F.; Loewenstein, G. Adam Smith, behavioral economist. J. Econ. Perspect. 2005, 19, 131-145. [CrossRef]

20. Thaler, R.H. From Cashews to Nudges: The Evolution of Behavioral Economics. Am. Econ. Rev. 2018, 108, 1265-1287. [CrossRef]

21. Smith, A. The Theory of Moral Sentiments [1759]; Liberty Classics: Indianapolis, IN, USA, 1981.

22. Smith, A. An Inquiry into the Nature and Causes of the Wealth of Nations [1776]; Liberty Classics: Indianapolis, IN, USA, 1981.

23. Keynes, J.M. The General Theory of Employment, Interest, and Money; Macmillan: London, UK, 1936.

24. Pareto, V. Manual of political economy: A critical and variorum translation edition. In Economic Equilibrium; Montesano, E.A., Zanni, A., Bruni, L., Chipman, J., McLure, M., Eds.; Oxford University Press: Oxford, UK, 2014; pp. $173-190$.

25. Cifuentes-Faura, J. The Importance of Behavioral Economics during COVID-19. J. Econ. Behav. Stud. 2020, 12, 70-74. [CrossRef]

26. Haushofer, J.; Metcalf, J.C.E. Combining Behavioral Economics and Infectious Disease Epidemiology to Mitigate the COVID-19 Outbreak; Princeton University: Princeton, NJ, USA, 2020; Volume 6, pp. 1-10.

27. Mian, A.; Khan, S. Coronavirus: The spread of misinformation. BMC Med. 2020, 18, 1-2. [CrossRef]

28. Cifuentes-Faura, J. Infodemics during COVID-19: Resources and recommendations to combat it. Online Inf. Rev. 2021, 45, 830-833. [CrossRef]

29. Roozenbeek, J.; Schneider, C.R.; Dryhurst, S.; Kerr, J.; Freeman, A.L.J.; Recchia, G.; van der Bles, A.M.; van der Linden, S. Susceptibility to misinformation about COVID-19 around the world. R. Soc. Open Sci. 2020, 7, 201199. [CrossRef]

30. Gigerenzer, G. How to make cognitive illusions disappear: Beyond "heuristics and biases". Eur. Rev. Soc. Psychol. 1991, 2, 83-115. [CrossRef]

31. Kahneman, D.; Slovic, S.P.; Slovic, P.; Tversky, A. (Eds.) Judgment under Uncertainty: Heuristics and Biases; Cambridge University Press: Cambridge, UK, 1982.

32. Haselton, M.G.; Nettle, D.; Murray, D.R. The Evolution of Cognitive Bias. Handb. Evol. Psychol. 2015, 1-20. Available online: https:/ / onlinelibrary.wiley.com/doi/full/10.1002/9781119125563.evpsych241 (accessed on 15 June 2021). [CrossRef]

33. Christensen-Szalanski, J.J.; Willham, C.F. The hindsight bias: A meta-analysis. Organ. Behav. Hum. Decis. Process. 1991, 48, 147-168. [CrossRef]

34. Roese, N.J.; Vohs, K.D. Hindsight bias. Perspect. Psychol. Sci. 2012, 7, 411-426. [CrossRef]

35. Klayman, J. Varieties of Confirmation Bias. Psychol. Learn. Motiv. 1995, 32, 385-418. [CrossRef]

36. Oswald, M.E.; Grosjean, S. Confirmation bias. In Cognitive Illusions. A Handbook on Fallacies and Biases in Thinking, Judgement and Memory; Psychology Press: Hove, UK, 2004; Volume 79, p. 83.

37. Sharot, T. The optimism bias. Curr. Biol. 2011, 21, 941-945. [CrossRef]

38. Sharot, T.; Riccardi, A.M.; Raio, C.M.; Phelps, E.A. Neural mechanisms mediating optimism bias. Nature 2007, 450, 102-105. [CrossRef]

39. O'Donoghue, T.; Rabin, M. Present Bias: Lessons Learned and To Be Learned. Am. Econ. Rev. 2015, 105, 273-279. [CrossRef]

40. Genesove, D.; Mayer, C. Loss Aversion and Seller Behavior: Evidence from the Housing Market. Q. J. Econ. 2001, 116, 1233-1260. [CrossRef]

41. Tversky, A.; Kahneman, D. The framing of decisions and the psychology of choice. Science 1981, 211, 453-458. [CrossRef] [PubMed]

42. Kahneman, D.; Knetsch, J.L.; Thaler, R.H. Anomalies: The Endowment Effect, Loss Aversion, and Status Quo Bias. J. Econ. Perspect. 1991, 5, 193-206. [CrossRef]

43. Howard, J. Bandwagon effect and authority bias. In Cognitive Errors and Diagnostic Mistakes; Springer: Cham, Switzerland, 2019; pp. 21-56.

44. Langer, E.J. The illusion of control. J. Pers. Soc. Psychol. 1975, 32, 311. [CrossRef]

45. Budescu, D.V.; Bruderman, M. The relationship between the illusion of control and the desirability bias. J. Behav. Decis. Mak. 1995, 8, 109-125. [CrossRef]

46. Phillips-Wren, G.; Power, D.J.; Mora, M. Cognitive bias, decision styles, and risk attitudes in decision making and DSS. J. Decis. Syst. 2019, 28, 63-66. [CrossRef]

47. Hoppe, E.I.; Kusterer, D.J. Behavioral biases and cognitive reflection. Econ. Lett. 2011, 110, 97-100. [CrossRef]

48. Luo, G.Y. Conservatism bias in the presence of strategic interaction. Quant. Financ. 2013, 13, 989-996. [CrossRef] 
49. Landucci, F.; Lamperti, M. A pandemic of cognitive bias. Intensiv. Care Med. 2021, 47, 636-637. [CrossRef]

50. Fogg, B. A behavior model for persuasive design. In Proceedings of the 4th International Conference on Persuasive Technology, Claremont, CA, USA, 26-29 April 2009; ACM Press: New York, NY, USA, 2009. [CrossRef]

51. World Bank. How Countries Are Using EdTech. 2020. Available online: https://www.worldbank.org/en/topic/edutech/brief/ howcountries-are-using-edtech-to-support-remote-learning-during-the-covid-19-pandemic (accessed on 8 June 2021).

52. World Economic Forum. The COVID-19 Pandemic Has Changed Education Forever. This Is How. 2020. Available online: https://www.weforum.org/agenda/2020/04/coronavirus-education-global-covid19-online-digital-learning/ (accessed on 9 June 2021).

53. UNESCO. National Learning Platforms and Tools. 2020. Available online: https://en.unesco.org/covid19/educationresponse/ nationalresponses (accessed on 15 June 2021). 